(C) The Author(s), 2021. Published by Cambridge University Press on behalf of The Nutrition Society. This is an Open Access article, distributed under the terms of the Creative Commons Attribution-NonCommercial-ShareAlike licence (http://creativecommons.org/licenses/ by-nc-sa/4.0/), which permits non-commercial re-use, distribution, and reproduction in any medium, provided the same Creative Commons licence is included and the original work is properly cited. The written permission of Cambridge University Press must be obtained for commercial re-use.

\title{
Association of blood lead level with vitamin D binding protein, total and free 25-hydroxyvitamin D levels in middle-school children
}

\author{
Abdur Rahman ${ }^{1 *}$, Reem Al-Sabah ${ }^{2}$, Reem Jallad ${ }^{1}$ and Muddanna S. Rao ${ }^{3}$ \\ ${ }^{1}$ Department of Food Science and Nutrition, College of Life Sciences, Kuwait University, 5969, Safat 13060, Kuwait \\ ${ }^{2}$ Department of Community Medicine and Behavioural Sciences, Faculty of Medicine, Kuwait University, Kuwait, Kuwait \\ ${ }^{3}$ Department of Anatomy, Faculty of Medicine, Kuwait University, 24923, Safat 13110, Kuwait
}

(Submitted 13 February 2021 - Accepted 24 May 2021 - First published online 3 June 2021)

\section{Abstract}

A negative association between blood $\mathrm{Pb}$ level (BPbL) and vitamin $\mathrm{D}$ metabolites in occupationally exposed populations has been reported, but data from the general population are scarce. Furthermore, the association between BPbL and vitamin D binding protein (DBP) and free 25-hydroxyvitamin D (25(OH)D) has not been reported. We investigated the association of BPbL with DBP, total and free 25(OH)D in healthy adolescents ( $n$ 1347; age range 11-16 years) cross-sectionally selected from all Governorates of Kuwait, utilising multi-stage cluster random sampling. Pb in whole blood was analysed by inductively coupled plasma MS, and DBP with ELISA. Plasma 25(OH)D was analysed by LC-MS/MS, and free 25(OH)D was calculated utilising the levels and binding affinities of DBP and albumin for 25(OH)D. DBP was positively associated with $\mathrm{BPbL}(\beta=0 \cdot 81 ; 95 \% \mathrm{CI} 0 \cdot 14,0 \cdot 22 ; P<0 \cdot 001)$. A negative association between BPbL and total $25(\mathrm{OH}) \mathrm{D}$ was non-significant $(P=0.24)$ when BPbL was used as a continuous variable but was significant when used as quartiles $(P=0 \cdot 02)$. The negative association between $\mathrm{BPbL}$ and free $25(\mathrm{OH}) \mathrm{D}$ was significant whether $\mathrm{BPbL}$ was used as continuous, as quartiles or as cut-off point of $<5 \mu \mathrm{g} / \mathrm{dl}(0 \cdot 24 \mu \mathrm{mol} / \mathrm{l})$. In multinomial logistic regression, the odds of vitamin D insufficiency and deficiency were more than two-fold higher in the upper quartiles of BPbL compared with the lowest quartile. The negative correlation of BPbL with free $25(\mathrm{OH}) \mathrm{D}$ was more robust than its correlation with total 25(OH)D. Future studies must consider the levels of DBP when assessing the association between $\mathrm{Pb}$ and vitamin $\mathrm{D}$ metabolites.

\section{Key words: Lead: Adolescents: Vitamin D binding protein: 25-hydroxyvitamin D: Free 25-hydroxyvitamin D}

Vitamin D is a seco-steroid hormone that regulates several biological functions in the body, in addition to its well-established role in Ca homoeostasis and bone metabolism ${ }^{(1)}$. Whether endogenously synthesised from its precursor (7-dehydrocholesterol) in the skin or obtained from the diet, vitamin $\mathrm{D}$ is first hydroxylated by 25-hydroxylase and converted into 25-hydroxyvitamin $\mathrm{D}$ $(25(\mathrm{OH}) \mathrm{D})$. The subsequent hydroxylation by $1 \alpha$-hydroxylase converts this into the active hormone 1,25-dihydroxyvitamin $\mathrm{D}$ $\left(1,25(\mathrm{OH})_{2} \mathrm{D}\right) .25(\mathrm{OH}) \mathrm{D}$ is the major circulatory metabolite and is used as a biomarker for vitamin D status ${ }^{(1)}$. Because of its hydrophobic nature, all the different metabolites of vitamin D circulate in the blood bound to proteins, mainly vitamin $\mathrm{D}$ binding protein (DBP) and albumin. In particular, $>99 \%$ of serum $25(\mathrm{OH}) \mathrm{D}$ is bound to proteins, approximately $85 \%$ to DBP and approximately $15 \%$ to albumin ${ }^{(2,3)}$.

Vitamin D deficiency (VDD) is a global public health problem $^{(4)}$, with prevalence levels among adolescents reported as high as $85-98 \%$ in India ${ }^{(5,6)}$, and about $97 \%$ in Korea ${ }^{(7)}$. Studies among adolescents in the Gulf region of the Middle
East have also reported a very high prevalence of $\mathrm{VDD}^{(8)}$, including $96 \%$ in Saudi Arabia ${ }^{(9)}$. In Kuwait, $81 \%$ of adolescents were reported to be vitamin D deficient, with approximately $40 \%$ of adolescents having severe $\operatorname{VDD}^{(10)}$.

Several factors contribute to this high prevalence of VDD. These include, but are not limited to, sun avoidance behaviour due to high temperatures, cultural practices like clothing that covers most of the body (particularly in women) and the use of sunscreen. Exposure to environmental $\mathrm{Pb}$ has been suggested as one of the potential risk factors of VDD. A dramatic decrease in serum $25(\mathrm{OH}) \mathrm{D}$ levels in jewellery workers ${ }^{(11)}$ and in serum $1,25(\mathrm{OH})_{2} \mathrm{D}$ levels in battery manufacture workers ${ }^{(12)}$, who have increased occupational exposure to $\mathrm{Pb}$, has been reported. Studies in children with high $\mathrm{Pb}$ exposure demonstrated a significant negative association between blood $\mathrm{Pb}$ levels (BPbL) and $1,25(\mathrm{OH})_{2} \mathrm{D}$ concentration ${ }^{(13-16)}$, reporting that children whose $\mathrm{BPbL}$ were in the range of $33-55 \mu \mathrm{g} / \mathrm{dl}$ have a significant reduction in serum $1,25(\mathrm{OH})_{2} \mathrm{D}$ concentration. The decrease in serum $1,25(\mathrm{OH})_{2} \mathrm{D}$ was even more pronounced in children with $\mathrm{BPbL}$

Abbreviations: BPbL, blood lead level; DBP, vitamin D binding protein; 25(OH)D, 25-hydroxyvitamin D; IQR, interquartile range; VDD, vitamin D deficiency.

* Corresponding author: Abdur Rahman, fax +965-22513929, email abdurrahman.ahmad@ku.edu.kw 
of $>62 \mu \mathrm{g} / \mathrm{dl}$, suggesting a dose-dependent effect of $\mathrm{Pb}$ on vitamin D status ${ }^{(15)}$.

$\mathrm{Pb}$ is a toxic heavy metal that is ubiquitously present in our environment and is still being used in various industries ${ }^{(17,18)}$. $\mathrm{Pb}$ poisoning is a public health concern in both developing and developed countries ${ }^{(19)}$. Like VDD, the prevalence of elevated BPbL is also high in the Middle East in both adult and paediatric populations ${ }^{(20-22)}$. In Kuwait, more than $50 \%$ of newborns were reported to have BPbL higher than $10 \mu \mathrm{g} / \mathrm{dl}^{(23)}$. Our recent data show that over $50 \%$ of adolescents have $\mathrm{BPbL} \geq 5 \mu \mathrm{g} / \mathrm{dl}$ (manuscript submitted), the current CDC limit of concern.

Under normal physiological conditions, approximately $0.03 \%$ of total $25(\mathrm{OH}) \mathrm{D}$ and $0.4 \%$ of total $1,25(\mathrm{OH})_{2} \mathrm{D}$ are in the unbound form and it is this free (bioavailable) form of the vitamin that is taken up by most tissues ${ }^{(3)}$. As DBP has a high affinity for $25(\mathrm{OH}) \mathrm{D}$, a negative correlation has been reported between free $25(\mathrm{H}) \mathrm{D}$ and $\mathrm{DBP}^{(24)}$. Thus, in conditions where DBP levels are increased, a smaller amount of $25(\mathrm{OH}) \mathrm{D}$ will be available for tissue uptake ${ }^{(25)}$. DBP is a positive acute phase protein, the expression of which in the liver could be enhanced by proinflammatory cytokines like IL- $6^{(26)}$. $\mathrm{Pb}$ is a prooxidant metal and is known to cause inflammation and increases the production of proinflammatory cytokines like IL- $1 \beta$, TNF- $\alpha$ and interferon- $\gamma^{(27,28)}$. We therefore hypothesise that high BPbL will increase serum levels of DBP with a subsequent decrease in free 25(OH)D levels. However, to our knowledge, such associations between $\mathrm{BPbL}$ and serum $\mathrm{DBP}$ and free $25(\mathrm{OH}) \mathrm{D}$ have not been reported. Furthermore, a negative association between BPbL and vitamin D metabolites $(25(\mathrm{OH}) \mathrm{D}$ and $\left.1,25(\mathrm{OH})_{2} \mathrm{D}\right)$ in occupationally exposed populations has been reported, but data on this association in healthy populations are scarce.

The adolescent population in Kuwait comprises approximately one-quarter of the total population, and both VDD and elevated BPbL in this population are highly prevalent. The objectives of this study were thus to investigate, in a nationally representative sample of middle-school children, the association between $\mathrm{BPbL}$ and total $25(\mathrm{OH}) \mathrm{D}$, free $25(\mathrm{OH}) \mathrm{D}$ and $\mathrm{DBP}$. In this study, we tested the hypothesis that high BPbL is positively associated with DBP and negatively associated with total and free $25(\mathrm{OH}) \mathrm{D}$

\section{Materials and methods}

\section{Study design and protocol}

This was a cross-sectional study conducted in public middle schools randomly selected from all the six Governorates of Kuwait. Study subjects, in the age range of 11-16 years, were selected from twelve schools (six each for boys and girls) using stratified multi-stage cluster random sampling. The sample allocation in each governorate was based on the relative size of that governorate as judged by the total number of students in the governorate. The study was approved by The Ethics Committee at the Ministry of Health, Kuwait (No: 2015/248) as well as The Ethics Committee of the Health Sciences Centre, Kuwait University (No: DR/EC/2338). The study was conducted in accordance with the declaration of Helsinki ethical principles for medical research involving human subjects. An informed consent form was sent to the parents including permission to draw a blood sample from their child and a self-administered parental questionnaire with questions on various sociodemographic parameters. Informed consent forms and questionnaire were sent to 1583 households, of which 1422 returned the forms with written approval. Trained dedicated data collectors carried out face-to-face interviews with the students using a structured questionnaire. Details on the questionnaire development and validation have been previously published ${ }^{(10,29)}$. Upon verbal assent, a venous blood sample $(5 \mathrm{ml})$ was drawn from 1416 students (six subjects declined to give blood sample) by a highly trained paediatric nurse.

\section{Justification of sample size}

For this cross-sectional study, the estimated sample for the main effect (association between BPbL and 25(OH)D) was 1100 students, which was large enough to yield a study power of $90 \%$ to detect an increase of 0.009 in the coefficient of determination of the reduced model $\left(R^{2}=0.039\right)$ at a significance level of $5 \%$, while fitting a full model with nine predictors and with an assumed coefficient of determination as $0 \cdot 048$. To account for the missing data, we inflated our sample size to 1250 adolescents. Plasma 25(OH)D data were available for 1416 participants, whereas BPbL data were available for 1388 subjects. DBP was analysed in a subsample of 800 subjects randomly selected by a computer-generated programme, with similar representation from each sex and age group, and data were available for 703 subjects.

\section{Blood collection and analyses}

Plasma was separated for DBP and 25(OH)D analyses and stored at $-80^{\circ} \mathrm{C}$ until analysis. Plasma DBP was determined utilising a commercial ELISA kit from Immunodiagnostik (Cat. no. K2314; Immunodiagnostik AG) as per the manufacturer's instructions. The assay has an intra-assay $\mathrm{CV}$ of $5.0 \%$ at low concentration and $3.2 \%$ at high concentration. The inter-assay $\mathrm{CV}$ is $12.7 \%$. The detection limit is $1.23 \mathrm{ng} / \mathrm{ml}$. Pb in whole blood samples $(0.5 \mathrm{ml})$, digested in perchloric acid/nitric acid (1:5) solution, was analysed with Inductively Coupled Plasma MS. Double-deionised water was used in all sample preparation steps to avoid contamination. For quality control check, lyophilised whole blood samples of known mineral content (Clin-Check-Control, Cat. no. 884042; Recipe) were included in the analyses. Samples for $25(\mathrm{OH}) \mathrm{D}$ analysis were protected from light throughout handling and processing. Plasma $25(\mathrm{OH}) \mathrm{D}$ was measured in a CAP-accredited laboratory by LC-tandem MS (LC-MS/MS), as described previously ${ }^{(30)}$ using the commercially available kit from Chromsystems (Cat. no. 2000/1000/F; Chromsystems Instruments \& Chemicals GmbH). Precision and accuracy of analysis were monitored by including control samples (MassCheck controls). For defining vitamin D status categories, we used the $25(\mathrm{OH}) \mathrm{D}$ cut-off values of the Endocrine Society and the Society for Adolescent Health and Medicine as follows: VDD $<50 \mathrm{nmol} / 1(20 \mathrm{ng} / \mathrm{ml})$; vitamin D insufficiency $50-75 \mathrm{nmol} / \mathrm{l}(20-30 \mathrm{ng} / \mathrm{ml})$ and vitamin D 
sufficiency $\geq 75 \mathrm{nmol} / 1(30 \mathrm{ng} / \mathrm{ml})$. The following formula, described by Tsuprykov et $a l .{ }^{(31)}$, was used to calculate free 25(OH)D:

Free $25(\mathrm{OH}) \mathrm{D}=$ total $25(\mathrm{OH}) \mathrm{D} / 1+\left(6 \times 10^{5} \times\right.$ albumin $)+$ $\left(7 \times 10^{8} \times \mathrm{DBP}\right)$

\section{Statistical analyses}

Data were double-entered into a database using Epidata Entry. Data for BPbL, 25(OH)D and BPB were not normally distributed. These data are presented as median and interquartile range (IQR). Mean differences in these variables were estimated with Mann-Whitney $U$ test, Kruskal-Wallis test or median test, as appropriate. BPbL was divided into quartiles and also based on the cut-off points of $\geq 5 \mu \mathrm{g} / \mathrm{dl}$. Free $25(\mathrm{OH})$ was $\log$ transformed for normalisation. Mean differences of free $25(\mathrm{OH}) \mathrm{D}$ across $\mathrm{Pb}$ categories were estimated by $t$ test for independent samples and one-way ANOVA. Linear regression was used to assess the association of PBbL with total 25(OH)D and free $25(\mathrm{OH}) \mathrm{D}$, using $\mathrm{BPbL}$ either as continuous variable, as quartiles or as categorised by the cut-off point of $5 \mu \mathrm{g} / \mathrm{dl}$. We also categorised total $25(\mathrm{OH}) \mathrm{D}$ levels into two categories (insufficient/ sufficient (combined) and deficient groups) and used binary logistic regression to assess the association between BPbL

Table 1. Sociodemographic characteristics and nutritional status of the study participants categories and VDD. A $P<0.05$ was used for statistical significance. Data were analysed with SPSS version 26.

\section{Results}

Sociodemographic and nutritional characteristics of the study participants are presented in Table $1 . \mathrm{Pb}$ and $25(\mathrm{OH}) \mathrm{D}$ data were available for 1347 subjects. Median 25(OH)D level was $29 \cdot 7$ (IQR 19.2-44.2) nmol/l, with $81 \cdot 2 \%$ subjects having deficient $(<50 \mathrm{nmol} / \mathrm{l})$ 25(OH)D levels. Median BPbL was 5.1 (IQR $3 \cdot 6-7 \cdot 1) \mu \mathrm{g} / \mathrm{dl}(4.9(\mathrm{IQR} 3 \cdot 8-6 \cdot 5) \mu \mathrm{g} / \mathrm{dl}$ in males and 5.4 $(3.3-7.6) \mu \mathrm{g} / \mathrm{dl}$ in females; $P=0.001)$, and $51 \%$ of the subject has $\mathrm{BPbL} \geq 5 \mu \mathrm{g} / \mathrm{dl}$ (the CDC cut-off level of toxicity). There was a non-significant negative correlation between BPbL and plasma total $25(\mathrm{OH}) \mathrm{D}$ levels $(\beta=-0 \cdot 05 ; P=0.09)$. Distribution of total $25(\mathrm{OH}) \mathrm{D}$ levels across different quartiles and cut-off points of BPbL is shown in Fig. 1. Median 25(OH)D levels were 28.0 (IQR 18.6-45.5), 31.9 (IQR 22.3-45.2), 30.0 (IQR 19.3-43.6) and 26.9 (IQR 18.3-40.1) nmol/1 in Q1, Q2, Q3 and Q4, respectively $(P=0.02)$. Similarly, median $25(\mathrm{OH}) \mathrm{D}$ levels in subject with $\mathrm{BPbL}<5 \mu \mathrm{g} / \mathrm{dl}$ was $30 \cdot 5$ (IQR 19.7-45.3) nmol/l and $28.2($ IQR $18 \cdot 8-41.9) \mathrm{nmol} / \mathrm{l}$ in subject with $\mathrm{BPbL} \geq 5 \mu \mathrm{g} / \mathrm{dl}$ $(P=0 \cdot 08)$. As data on DBP were available for 703 subjects, free $25(\mathrm{OH}) \mathrm{D}$ was calculated for the same number of subjects.

(Mean values and standard deviation; numbers and percentages; median and interquartile ranges (IQR))

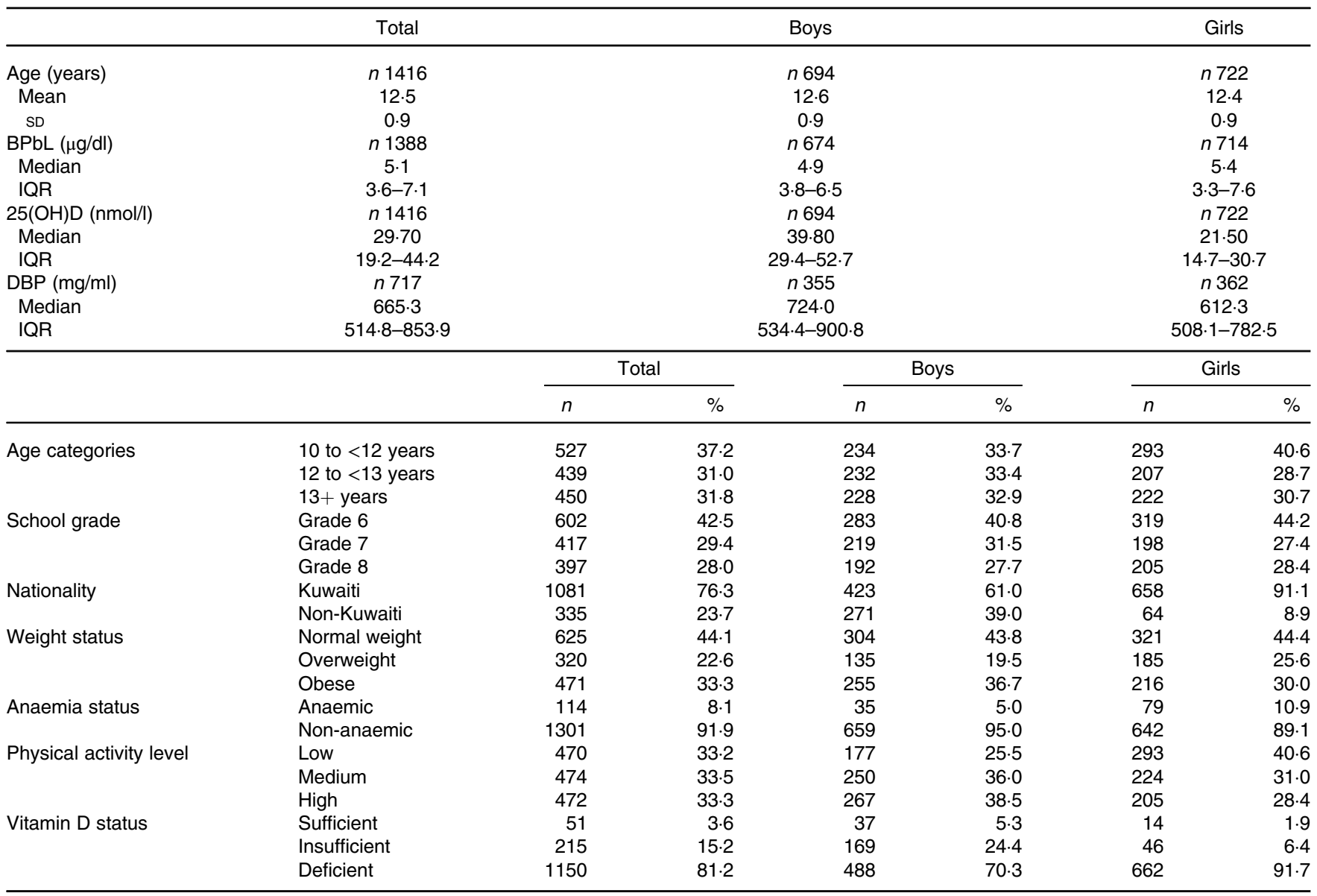


(a)

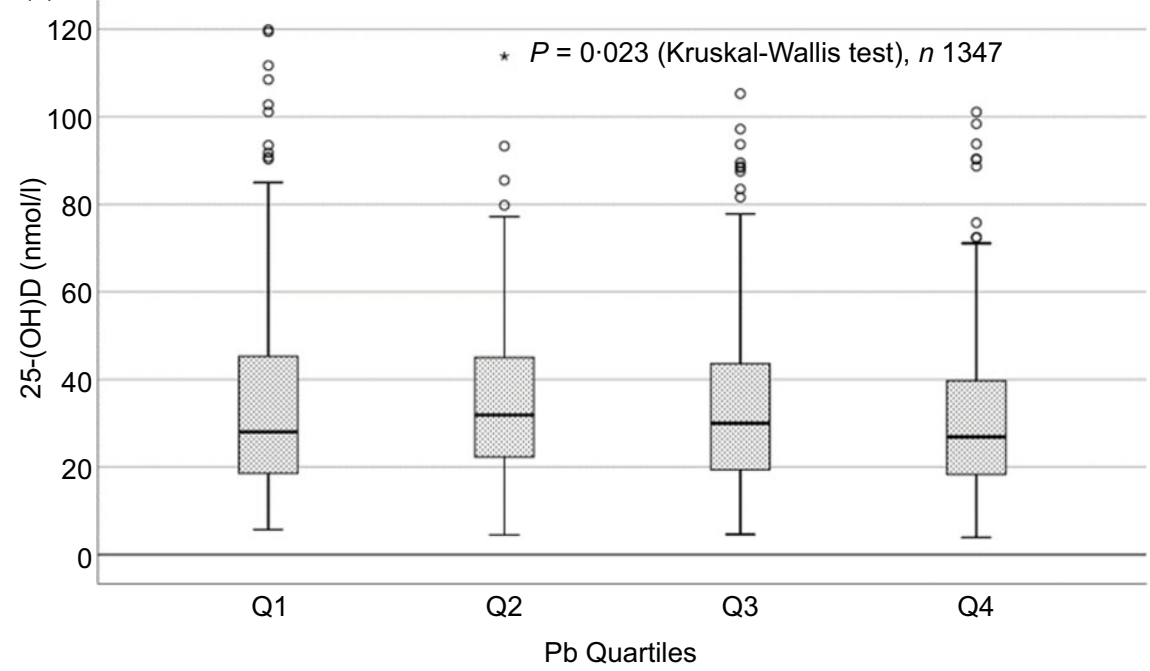

(b)

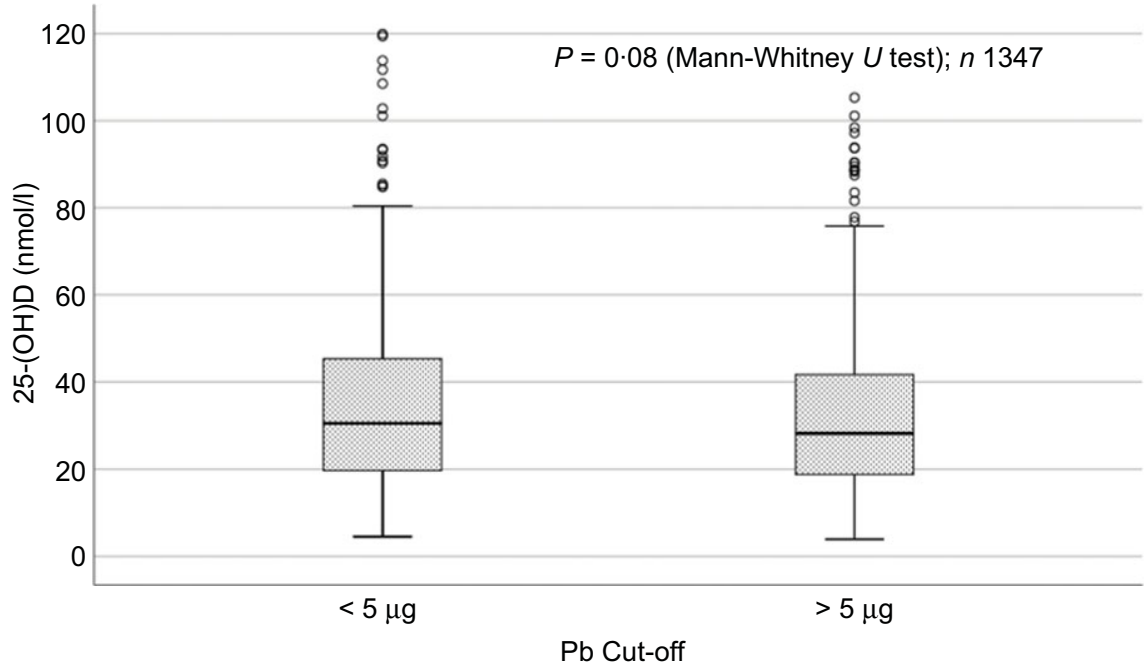

Fig. 1. Box plot showing the distribution of plasma total 25 -hydroxyvitamin $D(25(\mathrm{OH}) \mathrm{D})$ levels across quartiles of blood lead levels (a), and lead levels categorised based on the CDC cut-off of $5 \mathrm{ug} / \mathrm{dl}(\mathrm{b})$. Data were analysed by Kruskal-Wallis test in A and by Mann-Whitney $U$ test in $\mathrm{B}$.

Distribution of free 25(OH)D levels across different quartiles and cut-off points of BPbL is shown in Fig. 2. Geometric mean free 25(OH)D levels were 3.97 (SD 2.01), 3.52 (SD 1.89), 3.27 (sD 1.95) and 3.05 (sD 1.95) $\mathrm{pmol} / 1$ in $\mathrm{Q} 1, \mathrm{Q} 2, \mathrm{Q} 3$ and Q4, respectively $(P=0.002)$. Geometric mean levels of free $25(\mathrm{OH}) \mathrm{D}$ in subject with $\mathrm{BPbL}<5 \mu \mathrm{g} / \mathrm{dl}$ were 3.78 (sD 1.97) $\mathrm{pmol} / \mathrm{l}$ and 3.15 (sD 1.94) $\mathrm{pmol} / \mathrm{l}$ in subject with $\mathrm{BPbL} \geq 5 \mu \mathrm{g} / \mathrm{dl}(P \leq 0 \cdot 001)$. Figure 3 shows the distribution of DBP across different quartiles and cut-off points of BPbL. Median DBP were 584 (IQR 466-620), 724 (IQR 521-889), 782 (IQR 627-881) and 779 (IQR 545-937) $\mathrm{mg} / \mathrm{l}$ in Q1, Q2, Q3 and Q4, respectively $(P<0 \cdot 001)$. Median DBP levels in subject with $\mathrm{BPbL}<5 \mu \mathrm{g} / \mathrm{dl}$ was 566 (IQR 487-760) $\mathrm{mg} / \mathrm{l}$ and 784 (IQR 584-926) $\mathrm{mg} / \mathrm{l}$ in subject with $\mathrm{BPbL} \geq 5 \mu \mathrm{g} / \mathrm{dl}$ $(P<0.001)$. In the univariable linear regression analysis, significant positive association was observed between DBP and $\mathrm{Pb}$ ( $\beta=0.81$ (95\% CI $0.14,0.22) ; P<0.001 ; R^{2}=0.087$ ) (Fig. 4) and a negative association between DBP and free 25(OH)D
(Fig. 5) ( $\beta=-0.005$ (95\% CI $-0.006,-0.004) ; P<0.001)$. No significant association was found between $\mathrm{BPbL}$, used as continuous variable, and plasma total $25(\mathrm{OH}) \mathrm{D}$, either in the unadjusted model or when adjusted for the known factors that are associated with plasma vitamin D (Table 2). However, when BPbL were used as quartiles, significant negative association was found between $\mathrm{BPbL}$ quartiles and total $25(\mathrm{OH}) \mathrm{D}$, and this negative association remained significant when adjusted for the known factors associated with total 25(OH)D in this cohort (Table 2). When BPbL was used as a cut-off of $<5 \mu \mathrm{g} / \mathrm{dl}$ or $\geq 5 \mu \mathrm{g} / \mathrm{dl}$, the negative association was statistically significant in the univariable model. However, in the adjusted model, this association did not remain significant (Table 2). On the other hand, the negative association between $\mathrm{BPbL}$ and free $2(\mathrm{OH}) \mathrm{D}$ was significant whether $\mathrm{BPbL}$ was used as continuous variable, as quartiles or cut-off points in univariable as well as in multivariable models with adjustment for different potential confounding variables (Table 2). In multinomial regression, the odds of being 


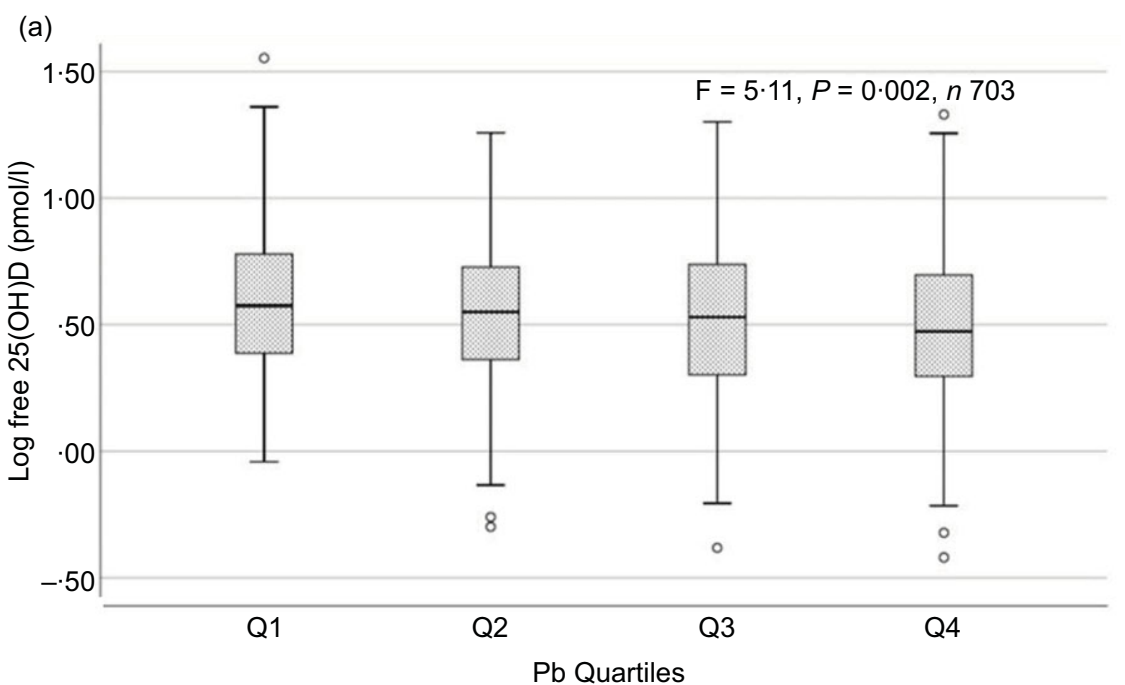

(b)

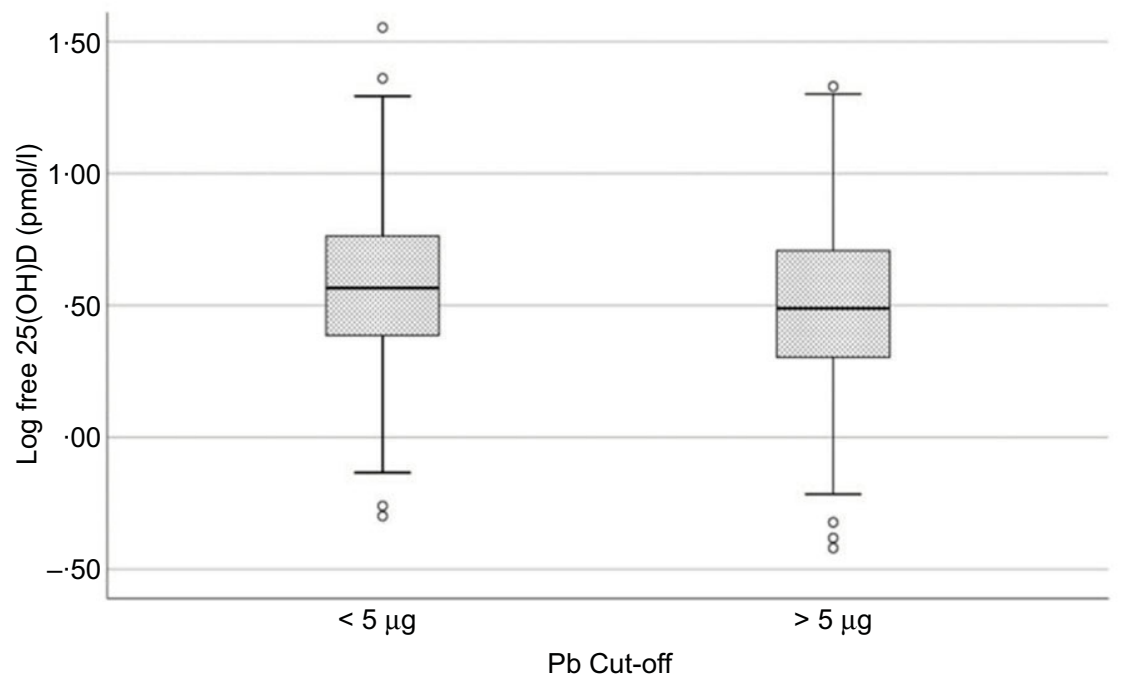

Fig. 2. Box plot showing the distribution of plasma free 25 -hydroxyvitamin $D(25(\mathrm{OH}) \mathrm{D})$ levels across quartiles of blood lead levels (a), and lead levels categorised based on the CDC cut-off of $5 \mathrm{ug} / \mathrm{dl}$ (b). Free 25(OH)D levels were log-transformed for normalisation. Data were analysed by one-way ANOVA in A and by $t$ test for independent samples in B.

vitamin $\mathrm{D}$ insufficient was significantly higher in the Q2 (compared with Q1) of $\mathrm{BPbL}(\mathrm{OR}=2.96(95 \% \mathrm{CI} 1 \cdot 20,7 \cdot 31)$ ). On the other hand, the odds of being vitamin $\mathrm{D}$ deficient were significantly higher in both Q2 and Q4 (compared with Q1) of BPbL $(\mathrm{OR}=2.53(95 \%$ CI $1.09,5.84)$ and $(2.71$ (95\% CI 1.17, 6.24), respectively, for Q2 and Q4) (Table 3). The distribution of BPbL across the different categories of vitamin $\mathrm{D}$ status is shown in Fig. 6(a). Although the median BPbL in the three categories of vitamin D status was not significantly different $(P=0 \cdot 09)$, the distribution of $\mathrm{BPbL}$ in the vitamin D-deficient group was significantly different from the sufficient group (Mann-Whitney $U$ test $P=0 \cdot 048$ ). The distribution of $\mathrm{BPbL}$ across the tertiles of free 25(OH)D (Fig. 6(b)) was significantly different $(P=0 \cdot 008)$.

\section{Discussion}

The main findings of this study can be summarised as follows: (1) high BPbL are associated with low levels of total and free
25(OH)D, (2) high BPbL are associated with high levels of DBP and (3) the negative association of BPbL with free $25(\mathrm{OH}) \mathrm{D}$ is more robust compared with its association with total $25(\mathrm{OH}) \mathrm{D}$. The negative association between vitamin $\mathrm{D}$ metabolites and BPbL has been supported by data from animal studies in which $\mathrm{Pb}$ ingestion decreased serum concentration of $1,25(\mathrm{OH})_{2} \mathrm{D}$ and blocked vitamin $\mathrm{D}$-dependent intestinal $\mathrm{Ca}$ transport in rats ${ }^{(32)}$. High $\mathrm{BPbL}$ has been suggested to cause disruption of the renal hydroxylation of $25(\mathrm{OH}) \mathrm{D}$ by 1 - $\alpha$-hydroxylase to produce the active form $1,25(\mathrm{OH})_{2} \mathrm{D}^{(33)}$. Similarly, exposure of rat pups to $\mathrm{Pb}$ resulted in significant reduction in serum $25(\mathrm{OH}) \mathrm{D}$ and $1,25(\mathrm{OH})_{2} \mathrm{D}$ with concomitant decrease in the expression of hepatic 25-hysroxylase and renal 1 - $\alpha$-hydroxylase ${ }^{(34)}$. The relationship between vitamin $\mathrm{D}, \mathrm{Ca}$ and $\mathrm{Pb}$ is complex ${ }^{(35)}$. Some studies reported that elevated $\mathrm{BPbL}$ are associated with increased $1,25(\mathrm{OH})_{2} \mathrm{D}$, as a compensatory response to lower Ca absorption ${ }^{(3)}$. Other studies suggested that vitamin $\mathrm{D}$ facilitates $\mathrm{Pb}$ absorption especially in suboptimal 

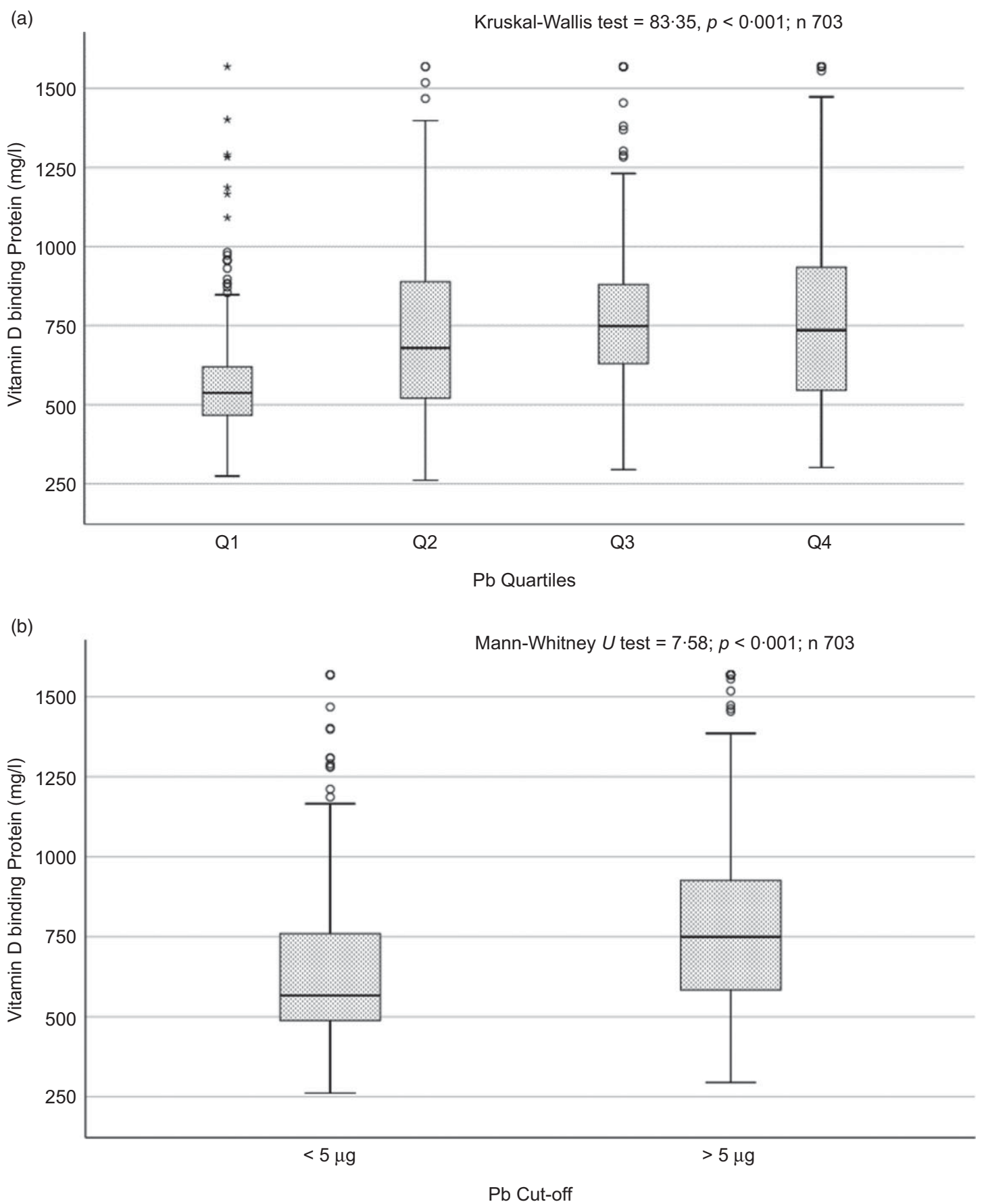

Fig. 3. Box plot showing the distribution of vitamin D binding protein (DBP) across quartiles of blood lead levels (a), and lead levels categorised based on the CDC cut-off of $5 \mathrm{ug} / \mathrm{dl}(\mathrm{b})$. Data were analysed by Kruskal-Wallis test in A and by Mann-Whitney $U$ test in $\mathrm{B}$.

status of $\mathrm{Ca}$ and other minerals, which increase the risk of adverse clinical outcomes ${ }^{(32,33,37)}$. In rats, diet-induced VDD increased $\mathrm{Pb}$ absorption and vitamin $\mathrm{D}$ repletion decreased $\mathrm{Pb}$ body retention, suggesting possible relation between low vitamin $\mathrm{D}$ and increased $\mathrm{Pb}$ absorption ${ }^{(38)}$. Our data do not support this later notion, as lower vitamin D levels were associated with high BPbL. Several other studies have reported similar lower BPbL levels in subjects with sufficient vitamin D levels ${ }^{(16,33,39,40)}$.
The negative association between BPbL and total 25(OH)D in this study was not statistically significant when BPbL was used as a continuous variable. Similar to our results, no association was found between BPbL and vitamin D among Mexican adolescents who had a mean BPbL of $4.6 \mu \mathrm{g} / \mathrm{dl}^{(41)}$. On the other hand, negative association was reported between vitamin $\mathrm{D}$ metabolites and $\mathrm{BPbL}$ in several studies in which $\mathrm{BPbL}$ were in the range of 12 to $>60 \mu \mathrm{g} / \mathrm{dl}^{(11-15)}$. In comparison with these studies which reported significant negative association, median BPbL in our 


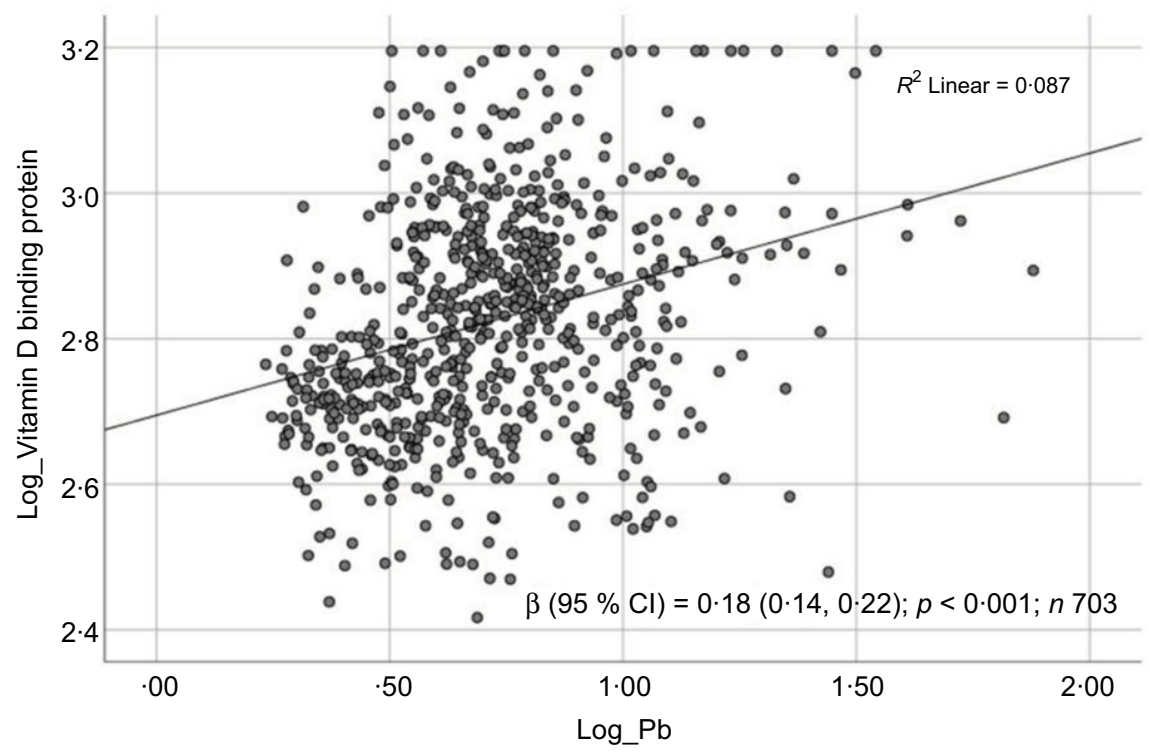

Fig. 4. Scatter plot showing the association between log-transformed vitamin $D$ binding protein (DBP) and log-transformed blood lead level (BPbL). The coefficient $(\beta)$ is in log units.

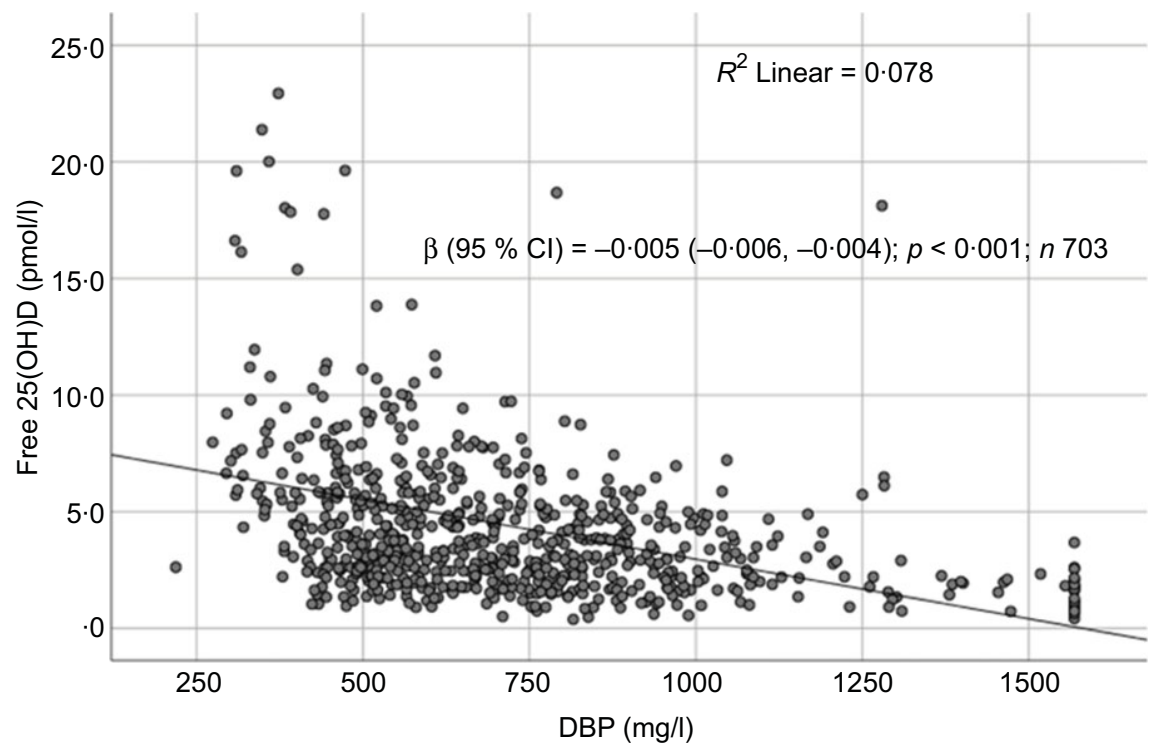

Fig. 5. Scatter plot showing the association between free 25-hydroxyvitamin $\mathrm{D}(25(\mathrm{OH}) \mathrm{D})$ and vitamin $\mathrm{D}$ binding protein (DBP).

study were lower $(5 \cdot 1 \mu \mathrm{g} / \mathrm{dl})$, which may explain the lack of statistical significance in association when BPbL was used as a continuous variable. In our sample, $<3 \%$ of subjects had $\mathrm{BPbL}$ of $>20 \mu \mathrm{g} / \mathrm{dl}$. This suggests a dose-dependent negative association between BPbL and vitamin D metabolites. This notion is further supported by the fact that when we used $\mathrm{BPbL}$ as quartiles, the negative association between $\mathrm{BPbL}$ and total $25(\mathrm{OH}) \mathrm{D}$ became significant, even in the model adjusted for the known confounding variables. Differences in the age of the study participants, duration of exposure and the measured vitamin D metabolite (whether 25(OH)D or $\left.1,25(\mathrm{OH})_{2} \mathrm{D}\right)$ could also be a factor in the strength of negative association observed in our study compared with the previous studies. Most of the previous studies are based on either younger children or older adults, as compared with our study which was based on subjects in the middle adolescence.

In this study, children who had median $\mathrm{BPbL}$ in the range of $3 \cdot 6-5 \cdot 1 \mu \mathrm{g} / \mathrm{dl}(\mathrm{Q} 2)$ had almost three-fold increased odds of having vitamin $\mathrm{D}$ insufficiency compared with those whose BPbL was $<3.6 \mu \mathrm{g} / \mathrm{dl}$ (Q1). Similarly, the odds of VDD were more than two-fold higher in the upper quartiles of BPbL compared with the lowest quartile $(\mathrm{OR}=2.53$ in $\mathrm{Q} 2$ and 2.71 in $\mathrm{Q} 4)$. Similar to our results, in a Chinese population study, VDD and vitamin $D$ insufficiency were significantly higher among children (age range 6 months to 14 years) with $\mathrm{BPbL} \geq 10 \mu \mathrm{g} / \mathrm{dl}$, while children who had $\mathrm{BPbL}<5 \mu \mathrm{g} / \mathrm{dl}$ were significantly more likely to have sufficient vitamin D levels ${ }^{(16)}$. 
Table 2. Association between $\mathrm{Pb}$ and vitamin $\mathrm{D}$ in linear regression analysis* (Odd ratio and $95 \%$ confidence intervals)

\begin{tabular}{|c|c|c|c|c|}
\hline & Coefficient $(\beta)$ & $95 \% \mathrm{Cl}$ (Lower, Upper bound) & $P$ & $R^{2}$ \\
\hline \multicolumn{5}{|l|}{ Total 25(OH)D } \\
\hline \multicolumn{5}{|l|}{ Model 1} \\
\hline $\mathrm{Pb}(\mu \mathrm{g} / \mathrm{dl})$ & -0.12 & $-0.33,-0.08$ & $0 \cdot 24$ & 0.001 \\
\hline $\mathrm{Pb}$ quartiles & $-1 \cdot 14$ & $-2.57,-0.27$ & 0.02 & 0.004 \\
\hline Pb cut-off $(5 \mu \mathrm{g} / \mathrm{dl})$ & -3.0 & $-5.57,-0.43$ & 0.02 & 0.004 \\
\hline \multicolumn{5}{|l|}{ Model 2} \\
\hline $\mathrm{Pb}(\mu \mathrm{g} / \mathrm{dl})$ & -0.09 & $-0.28,1.01$ & 0.35 & 0.234 \\
\hline $\mathrm{Pb}$ quartiles & $-1 \cdot 12$ & $-2 \cdot 20,-0 \cdot 21$ & 0.04 & 0.485 \\
\hline $\mathrm{Pb}$ cut-off $(5 \mu \mathrm{g} / \mathrm{dl})$ & $-1 \cdot 34$ & $-3 \cdot 75,1.07$ & $0 \cdot 275$ & 0.483 \\
\hline \multicolumn{5}{|l|}{ Free $25(\mathrm{OH}) \mathrm{D}$} \\
\hline \multicolumn{5}{|l|}{ Model 1} \\
\hline $\mathrm{Pb}(\mu \mathrm{g} / \mathrm{dl})$ & -0.005 & $-0.009,-0.001$ & 0.006 & 0.011 \\
\hline $\mathrm{Pb}$ quartiles & -0.037 & $-0.056,-0.018$ & $<0.001$ & 0.021 \\
\hline Pb cut-off $(5 \mu \mathrm{g} / \mathrm{dl})$ & -0.080 & $-0.123,-0.037$ & $<0.001$ & 0.019 \\
\hline \multicolumn{5}{|l|}{ Model 2} \\
\hline $\mathrm{Pb}(\mu \mathrm{g} / \mathrm{dl})$ & -0.003 & $-0.007,0.00$ & 0.048 & 0.048 \\
\hline $\mathrm{Pb}$ quartiles & -0.029 & $-0.047,-0.011$ & 0.002 & 0.002 \\
\hline $\mathrm{Pb}$ cut-off $(5 \mu \mathrm{g} / \mathrm{dl})$ & -0.055 & $-0.095,0.014$ & 0.008 & 0.008 \\
\hline
\end{tabular}

* Model 1 is unadjusted; model 2 is adjusted for sex, age categories, governorate, father education, passive smoking, taking supplements, consumption of sugary drinks, number of times walking to school per week and BMl categories. Free 25-hydroxyvitamin $\mathrm{D}((25)(\mathrm{OH}) \mathrm{D})$ was log-transformed for regression analysis.

Table 3. Odds of vitamin D insufficiency and deficiency across quartiles of blood lead level (BPbL)* (Odds ratio and $95 \%$ confidence intervals)

\begin{tabular}{lllcr}
\hline & Pb quartiles & OR & 95\% Cl (Upper bound, Lower bound) \\
\hline Vitamin D insufficiency & Q1 $(<3.6 \mu \mathrm{g} / \mathrm{dl})$ & 1.00 & Ref & $1.20,7.31$ \\
& Q2 $(3.6-5.1 \mu \mathrm{g} / \mathrm{dl})$ & 2.96 & $0.80,4.07$ & 0.02 \\
& Q3 $(5.1-7.1 \mu \mathrm{g} / \mathrm{dl})$ & 1.80 & $0.79,5.00$ & 0.17 \\
Vitamin D deficiency & Q4 $(>7.1 \mu \mathrm{g} / \mathrm{dl})$ & 1.99 & Ref & 0.14 \\
& Q1 $(<3.6 \mu \mathrm{g} / \mathrm{dl})$ & 1.00 & $0.81,3.52$ & 0.03 \\
& Q2 $(3.6-5.1 \mu \mathrm{g} / \mathrm{dl})$ & 2.53 & $1.17,6.24$ & 0.16 \\
& Q3 $(5.1-7.1 \mu \mathrm{g} / \mathrm{dl})$ & 1.69 & & 0.02 \\
& Q4 $(>7.1 \mu \mathrm{g} / \mathrm{dl})$ & 2.71 & & \\
\hline
\end{tabular}

* In multinomial logistic regression, 25(OH)D was categorised into sufficient, insufficient and deficient categories and used as independent variable against. Vitamin D sufficiency was used as the reference category.

A small fraction of total plasma $25(\mathrm{OH}) \mathrm{D}$ (about $0 \cdot 03 \%$ ) is in the unbound form, which is bioavailable for uptake by most tissues. Thus, any factor that affects the ratio of free:bound $25(\mathrm{OH})$ $\mathrm{D}$ will have significant physiological consequences. DBP is a multi-functional, moderately abundant protein in the serum of vertebrates and is highly expressed in the liver ${ }^{(42)}$. The level of free $25(\mathrm{OH}) \mathrm{D}$ depends on the concentration of DBP. In conditions in which DBP levels are elevated, more $25(\mathrm{OH}) \mathrm{D}$ will be protein bound and less available for tissue uptake ${ }^{(25)}$. DBP levels may be affected by $\mathrm{Pb}$ in two ways. First, $\mathrm{DBP}$ is considered as a positive acute phase protein, whose level can be increased in inflammatory conditions. Chronic low-grade inflammation caused by $\mathrm{Pb}$ may elevate DBP levels and thus could result in lower levels of free $25(\mathrm{OH}) \mathrm{D}^{(27,28)}$. This hypothesis is supported by our findings of a positive association with DBP and a negative association with free $25(\mathrm{OH}) \mathrm{D}$. Second, DBP is produced in the liver and is filtered out of the kidneys and reabsorbed in the renal tubules ${ }^{(42)}$. Due to the hepatotoxicity and nephrotoxicity caused by high levels of $\mathrm{Pb}^{(43,44)}$, the production of DBP by the liver and the capacity of the kidneys to reabsorb DBP might be compromised, resulting in low blood DBP levels ${ }^{(45)}$, and thus lower total $25(\mathrm{OH})$ levels. $\mathrm{DBP}$ is also important for the renal hydroxylation of $25(\mathrm{OH}) \mathrm{D}$ to $1,25(\mathrm{OH})_{2} \mathrm{D}^{(42)}$. However, as the median $\mathrm{BPbL}$ were relatively low in our study, this mechanism does not seem to be relevant in this population.

The negative association between $\mathrm{BPbL}$ and free $25(\mathrm{OH}) \mathrm{D}$ was more robust than the negative association between $\mathrm{BPbL}$ and total $25(\mathrm{OH}) \mathrm{D}$. This suggests that the association between $\mathrm{BPbL}$ and total 25(OH)D may be confounded by DBP and therefore studies that did not show an association between $\mathrm{BPbL}$ and total vitamin $\mathrm{D}$ metabolites, whether total $25(\mathrm{OH}) \mathrm{D}$ or $1,25(\mathrm{OH})_{2} \mathrm{D}$, may be interpreted with caution, and DBP levels must be taken into account in future studies.

In the linear regression analysis, using BPbL as quartiles, the effect size on total 25(OH)D levels appears to be small, although significant $(\beta=-1 \cdot 12 ; P=0 \cdot 04)$. Similarly, the difference in mean 25(OH)D levels between BPbL in Q1 and Q4 is small (35.5 (26.0) $v$. $31.4(19 \cdot 1) ; P=0.02)$. Although statistically significant, this small effect size appears unlikely to be important physiologically 
(a)

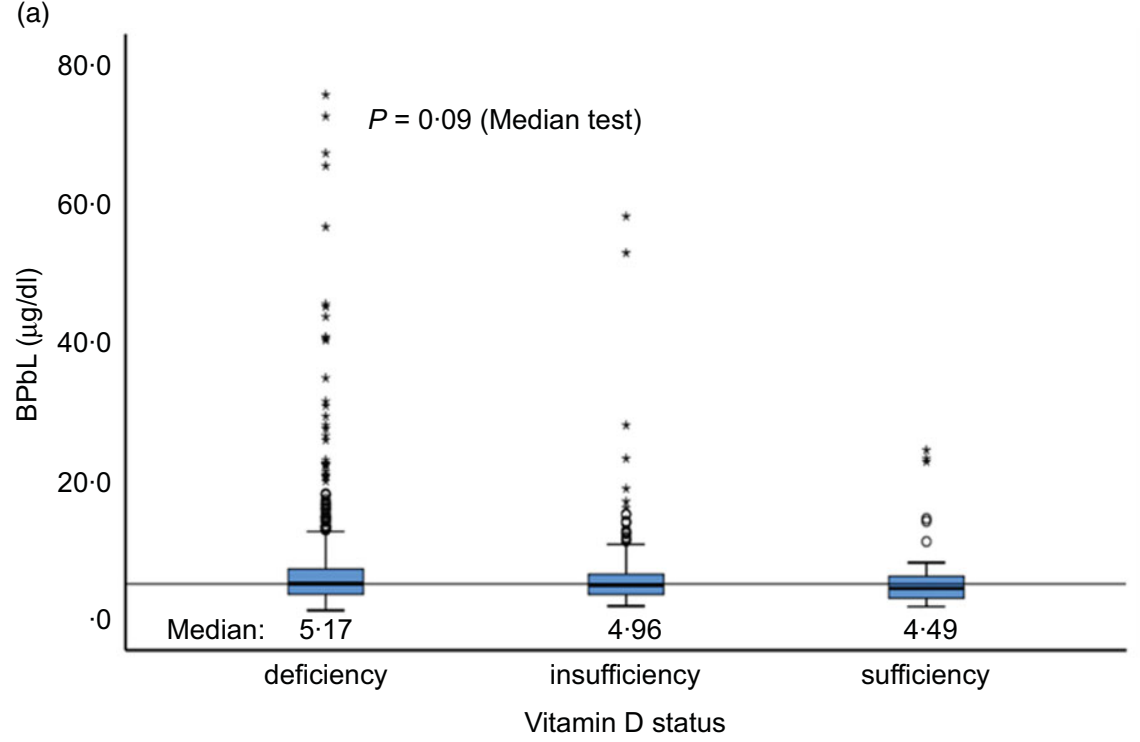

(b)

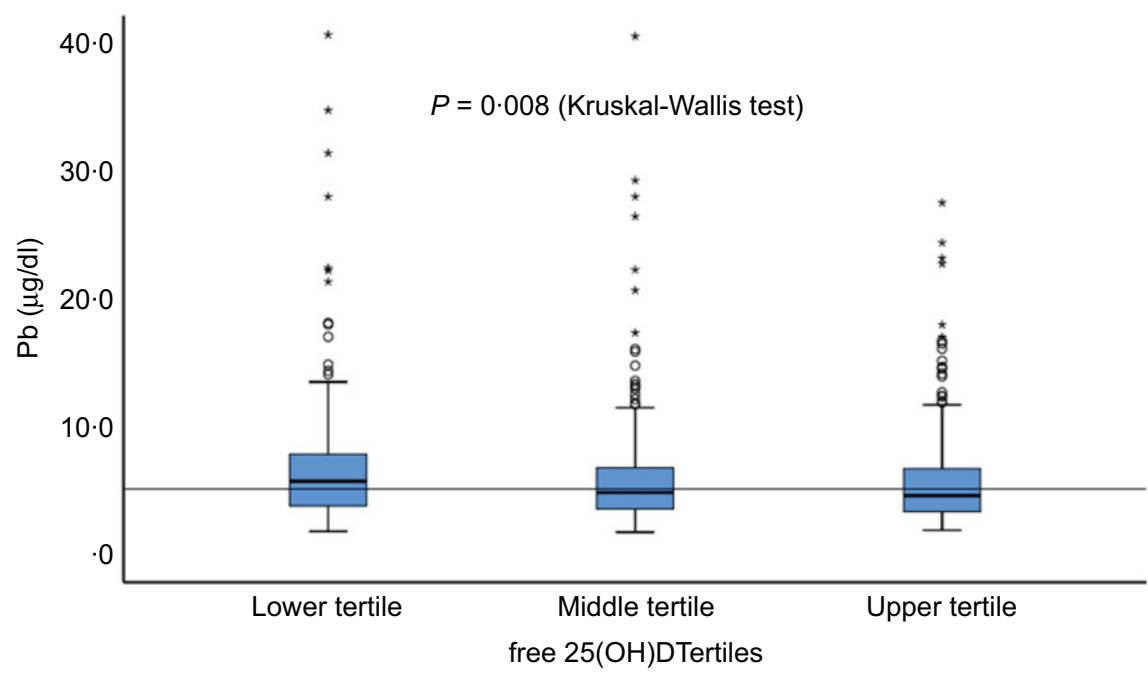

Fig. 6. Distribution of $B P b L$ among various categories of vitamin $D$ status. (a) Vitamin $D$ status categories based on total 25(OH)D levels. (b) Tertiles of free 25(OH)D. Horizontal line sows the overall median value of BPbL (5.1 $\mu \mathrm{g} / \mathrm{dl})$ ). $n 1100$ (deficient), 199 (insufficient) and 48 (sufficient). In (a), Mann-Whitney U test between sufficient and deficient groups is significant $(P=0.048)$. In (b), lower $v$. upper tertile, $P=0.003$, lower $v$. middle tertile, $P=0.026$; middle $v$. upper tertile, $P=0.44$.

at the individual level. However, in terms of classification as vitamin D insufficient or deficient, the difference between those who have $\mathrm{BPbL}$ in the lowest quartile (Q1) and those in the upper quartiles (Q2 and Q4) is more substantial, as the odds of being vitamin $\mathrm{D}$ insufficient or deficient are more than two-fold higher. Thus, from the public health point of view and population intervention, the effect size becomes quite significant

This study has several strengths. First, to our knowledge, this is the first study reporting a positive association between BPbL and DBP, and a robust negative association between BPbL and free $25(\mathrm{OH}) \mathrm{D}$. Second, we employed a very sensitive method of $\mathrm{Pb}$ estimation with strict quality control measures. Our method recovered $96.8 \%$ (S1) and $96 \%$ (S2) of $\mathrm{Pb}$ in the samples with known of $\mathrm{Pb}$ content (Seronorm). We also employed the gold standard method for 25(OH)D estimation (LC-MS/MS). Third, our study is based on a homogenous group of middle-school children with a narrow age range, thus eliminating any age-dependent effects. Fourth, this is one of the very few studies on a general population of healthy children. Most other studies on this topic are based on high-exposure groups and occupationally exposed populations. Fifth, our data are based on a nationally representative sample.

A limitation in this study is that we did not directly measure free $25(\mathrm{OH}) \mathrm{D}$ and our results are based on calculated free $25(\mathrm{OH}) \mathrm{D}$ values. It has been reported that calculated free $25(\mathrm{OH}) \mathrm{D}$ levels are generally higher than directly measured concentrations, particularly in subjects with some physiological conditions (like late pregnancy) and certain pathological conditions such as liver disease or cystic fibrosis ${ }^{(24)}$. The ELISA that we used for measuring DBP utilised polyclonal antibody. In healthy younger individuals, free 25(OH)D using DBP measured with polyclonal antibodies correlates reasonably well with the directly measured free $25(\mathrm{OH}) \mathrm{D}$, using either centrifugal 
ultrafiltration or the ELISA assay for free $25(\mathrm{OH}) \mathrm{D}^{(2)}$. As such, it is unlikely that the negative association between $\mathrm{BPbL}$ and free $(\mathrm{OH}) \mathrm{D}$ that we report here was compromised. Another potential limitation in this study is the lack of data on inflammatory markers like hsCRP. Such information could have strengthened our hypothesis of increased DBP levels due to the proinflammatory toxin, $\mathrm{Pb}$. Although we analysed hsCRP levels in a small sub sample ( $n$ 180), the sample size was too small to produce statistically meaningful results. For logistical reasons, we could not analyse hsCRP in more samples.

In conclusion, our data demonstrate that $\mathrm{BPbL}$ is positively correlated with $\mathrm{DBP}$ and negatively correlated with total and free (unbound) $25(\mathrm{OH}) \mathrm{D}$ in healthy children. The negative correlation of $\mathrm{BPbL}$ with free $25(\mathrm{OH}) \mathrm{D}$ was more robust than its correlation with total $25(\mathrm{OH}) \mathrm{D}$. These findings have few public health implications. First, the high prevalence of $\mathrm{Pb}$ toxicity may be a contributing factor in the very high prevalence of VDD in this population, and thus eliminating sources of $\mathrm{Pb}$ exposure may also improve vitamin D status, in addition to reducing other health risks associated with $\mathrm{Pb}$ toxicity. Additionally, countries having a high prevalence of both VDD and high BPbL among adolescents, such as Kuwait, should consider establishing clinical protocols to investigate $\mathrm{Pb}$ levels in those diagnosed with VDD, and to assess vitamin D levels in those diagnosed with high $\mathrm{Pb}$ levels. Given the high prevalence of both conditions, Kuwait should also assess the cost-effectiveness of screening adolescents for both conditions. Second, total plasma $25(\mathrm{OH})$ $\mathrm{D}$ may not be a sensitive biological marker for vitamin $\mathrm{D}$ status. Free (unbound) $25(\mathrm{OH})$ may be a better indicator of functional vitamin D status, particularly in situations with increased DBP level. However, methodological difficulties in measuring free $25(\mathrm{OH}) \mathrm{D}$ and the lack of a high-throughput assay at present hinder its use as a marker for vitamin D status. Further studies are needed to refine and develop a high-throughput assays for measuring free $25(\mathrm{OH}) \mathrm{D}$. Age- and sex-specific cut-offs of free $25(\mathrm{OH}) \mathrm{D}$ for classifying vitamin $\mathrm{D}$ status also need to be worked out.

\section{Acknowledgements}

We thank the Ministry of Education Kuwait and the management of participating schools for facilitating this study. We thank Ms. Smitha for her excellent technical assistance, and the department of Anatomy for facilitating $\mathrm{Pb}$ analysis. We also thank Dr. Joseph Longenecker for revising and editing the manuscript. Not applicable.

The study was approved by The Ethics Committee at the Ministry of Health, Kuwait (No: 2015/248) as well as The Ethics Committee of the Health Sciences Centre, Kuwait University (No: DR/EC/2338).

A. R. designed the study, contributed in data collection and analysis, wrote the manuscript, also responsible for the overall supervision of the project. R. S. designed the study, contributed in data collection and reviewed the manuscript. R. J. contributed in $\mathrm{Pb}$ measurement and data analysis. $\mathrm{M}$. R. contributed in $\mathrm{Pb}$ measurement and revised the manuscript.

The authors declare that they have no competing interests.

\section{References}

1. Chang SW \& Lee HC (2019) Vitamin D and health - the missing vitamin in humans. Pediatr Neonatol 60, 237-244.

2. Chun RF, Shieh A, Gottlieb C, et al. (2019) Vitamin D binding protein and the biological activity of vitamin D. Front Endocrinol 10, 718.

3. Bikle DD \& Schwartz J (2019) Vitamin D binding protein, total and free vitamin $\mathrm{D}$ Levels in different physiological and pathophysiological conditions. Front Endocrinol 10, 317.

4. van Schoor N \& Lips P (2017) Global overview of vitamin D status. Endocrinol Metab Clin North Am 46, 845-870.

5. Garg MK, Marwaha RK, Khadgawat R, et al. (2013) Efficacy of vitamin D loading doses on serum 25-hydroxy vitamin D levels in school going adolescents: an open label non-randomized prospective trial. J Pediatr Endocrinol Metab 26, 515-523.

6. Kapil U, Pandey RM, Goswami R, et al. (2017) Prevalence of Vitamin D deficiency and associated risk factors among children residing at high altitude in Shimla district, Himachal Pradesh, India. Indian J Endocrinol Metab 21, 178-183.

7. Byun EJ, Heo J, Cho SH, et al. (2017) Suboptimal vitamin D status in Korean adolescents: a nationwide study on its prevalence, risk factors including cotinine-verified smoking status and association with atopic dermatitis and asthma. BMJ Open 7, e016409.

8. Lips P, Cashman KD, Lamberg-Allardt C, et al. (2019) Current vitamin D status in European and Middle East countries and strategies to prevent vitamin D deficiency: a position statement of the European Calcified Tissue Society. Eur J Endocrinol 180, P23-P54.

9. AlBuhairan FS, Tamim H, Al Dubayee M, et al. (2015) Time for an adolescent health surveillance system in Saudi Arabia: findings from 'Jeeluna'. J Adolesc Health 57, 263-269.

10. Al-Taiar A, Rahman A, Al-Sabah R, et al. (2018) Vitamin D status among adolescents in Kuwait: a cross-sectional study. BMJ Open 8, e021401.

11. Mazumdar I, Goswami K \& Ali MS (2017) Status of serum calcium, vitamin D and parathyroid hormone and hematological indices among lead exposed jewelry workers in Dhaka, Bangladesh. Indian J Clin Biochem 32, 110-116.

12. Dongre NN, Suryakar AN, Patil AJ, et al. (2013) Biochemical effects of lead exposure on battery manufacture workers with reference to blood pressure, calcium metabolism and bone mineral density. Indian J Clin Biochem 28, 65-70.

13. Sorrell M \& Rosen JF (1977) Interactions of lead, calcium, vitamin D, and nutrition in lead-burdened children. Arch Environ Health 32, 160-164.

14. Rosen JF, Chesney RW, Hamstra A, et al. (1980) Reduction in 1,25-dihydroxyvitamin $\mathrm{D}$ in children with increased lead absorption. N Engl J Med 302, 1128-1131.

15. Mahaffey KR, Rosen JF, Chesney RW, et al. (1982) Association between age, blood lead concentration, and serum 1,25-dihydroxycholecalciferol levels in children. Am JClin Nutr 35, 1327-1331.

16. Chang L, Liu X, Shi $\mathrm{H}$, et al. (2014) Association of 25-hydroxyvitamin $\mathrm{D}$ with $\mathrm{Hb}$ and lead in children: a Chinese population-based study. Public Health Nutr 17, $827-832$.

17. CDC (2013) Blood lead levels in children aged 1-5 years United States, 1999-2010. MMWR Morb Mortal Wkly Rep 62, 245-248.

18. Kim HC, Jang TW, Chae HJ, et al. (2015) Evaluation and management of lead exposure. Ann Occup Environ Med 27, 30.

19. WHO (2010) Childhood Lead Poisoning. Geneva: World Health Organization. 
20. Shaik AP, Sultana SA \& Alsaeed AH (2014) Lead exposure: a summary of global studies and the need for new studies from Saudi Arabia. Dis Markers 2014, 415160

21. Al-Othman A, Al-Othman Z, El-Desoky G, et al. (2012) Lead in drinking water and human blood in Riyadh City, Saudi Arabia. Arabian J Geosci 6, 7.

22. Al-Mahroos F \& Al-Saleh F (2000) Umbilical cord blood lead level of newborns in Bahrain. Curr Paediatric Research 4, 6.

23. Rahman A, Al-Rashidi HA \& Khan AR (2012) Association of maternal blood lead level during pregnancy with child blood lead level and pregnancy outcome in Kuwait. Ecol Food Nutr 51, 40-57.

24. Schwartz JB, Lai J, Lizaola B, et al. (2014) A comparison of measured and calculated free $25(\mathrm{OH})$ vitamin D levels in clinical populations. J Clin Endocrinol Metab 99, 1631-1637.

25. Bikle DD, Gee E, Halloran B, et al. (1984) Free 1,25-dihydroxyvitamin D levels in serum from normal subjects, pregnant subjects, and subjects with liver disease. J Clin Invest 74, 1966-1971.

26. Lisowska-Myjak B, Jóźwiak-Kisielewska A, Łukaszkiewicz J, et al. (2020) Vitamin D-binding protein as a biomarker to confirm specific clinical diagnoses. Expert Rev Mol Diagn 20, 49-56.

27. Liu JT, Chen BY, Zhang JQ, et al. (2015) Lead exposure induced microgliosis and astrogliosis in hippocampus of young mice potentially by triggering TLR4-MyD88-NFKB signaling cascades. Toxicol Lett 239, 97-107.

28. Chibowska K, Baranowska-Bosiacka I, Falkowska A, et al. (2016) Effect of Lead (Pb) on Inflammatory Processes in the Brain. Int J Mol Sci 17, 2140.

29. Rahman A, Al-Taiar A, Shaban L, et al. (2018) Plasma 25-hydroxy vitamin $\mathrm{D}$ is not associated with either cognitive function or academic performance in adolescents. Nutrients 10, 1525.

30. Al-Harbi AN, Khan KM \& Rahman A (2017) Developmental vitamin $\mathrm{D}$ deficiency affects spatial learning in wistar rats. J Nutr 147, 1795-1805.

31. Tsuprykov O, Chen X, Hocher CF, et al. (2018) Why should we measure free $25(\mathrm{OH})$ vitamin D? I Steroid Biochem Mol Biol 180, 87-104.

32. Smith CM, DeLuca HF, Tanaka Y, et al. (1981) Effect of lead ingestion on functions of vitamin $\mathrm{D}$ and its metabolites. J Nutr 111, 1321-1329.
33. Schwalfenberg GK \& Genuis SJ (2015) Vitamin D, essential minerals, and toxic elements: exploring interactions between nutrients and toxicants in clinical medicine. Sci World J 2015 , 318595.

34. Rahman A, Al-Awadi AA \& Khan KM (2018) Lead affects vitamin D metabolism in rats. Nutrients $\mathbf{1 0}, 264$.

35. Fullmer CS (1997) Lead-Calcium interactions: involvement of 1,25-Dihydroxyvitamin D. Environ Res 72, 45-55.

36. Kristal-Boneh E, Froom P, Yerushalmi N, et al. (1998) Calcitropic hormones and occupational lead exposure. Am J Epidemiology 147, 458-463.

37. Edelstein S, Fullmer CS \& Wasserman RH (1984) Gastrointestinal absorption of lead in chicks: involvement of the cholecalciferol endocrine system. J Nutr 114, 692-700.

38. Barton JC, Conrad ME, Harrison L, et al. (1980) Effects of vitamin D on the absorption and retention of lead. Am JPhysiologyGastrointestinal Liver Physiol 238, G124-G130.

39. Jackson LW, Cromer BA \& Panneerselvamm A (2010) Association between bone turnover, micronutrient intake, and blood lead levels in pre-and postmenopausal women, NHANES 1999-2002. Environ Health Perspect 118, 1590-1596.

40. Arbuckle TE, Liang CL, Morisset A-S, et al. (2016) Maternal and fetal exposure to cadmium, lead, manganese and mercury: the MIREC study. Chemosphere 163, 270-282.

41. Zamoiski RD, Guallar E, García-Vargas GG, et al. (2014) Association of arsenic and metals with concentrations of 25-hydroxyvitamin D and 1,25-dihydroxyvitamin D among adolescents in Torreón, Mexico. Environ Health Perspect 122, 1233-1238.

42. White P \& Cooke N (2000) The multifunctional properties and characteristics of vitamin D-binding protein. Trends Endocrinol Metab 11, 320-327.

43. ATSDR (2020) Toxicological Profile of Lead: Agency for Toxic Substances and Disease Registry. https://www.atsdr.cdc.gov/ toxprofiles/tp13.pdf (accessed August 2020).

44. Rastogi SK (2008) Renal effects of environmental and occupational lead exposure. Indian J Occup Environ Med 12, 103-106.

45. Iruzubieta P, Terán Á, Crespo J, et al. (2014) Vitamin D deficiency in chronic liver disease. World J Hepatol 6, 901-915. 